\title{
Construction of twenty-six points specific optimum second order rotatable designs in three dimensions with a practical example
}

\author{
Tum Isaac Kipkosgei* \\ Department of Statistics and Computer Science, Moi University, P.O. Box 3900-30100,Eldoret, Kenya \\ *Corresponding author E-mail:isaactum@gmail.com
}

\begin{abstract}
This quadratic response surface methodology focuses on finding the levels of some (coded) predictor variables $\mathbf{x}_{=}\left(\mathrm{x}_{1 \mathrm{u}}, \mathrm{x}_{2 \mathrm{u}}, \mathrm{x}_{3 \mathrm{u}}\right)^{\prime}$ that optimize the expected value of a response variable yu from natural levels. The experiment starts from some best guess or "control" combination of the predictor variables (usually coded to $\mathrm{x}=0$ for this case $\mathrm{x} 1 \mathrm{u}=30, \mathrm{x} 2 \mathrm{u}=25$ and $\mathrm{x} 3 \mathrm{u}=40$ ) and experiment is performed varying them in a region around this center point.

We go further to construct a specific optimum second order rotatable design of three factors in twenty-six points. The achievement of this is done with estimation of the free parameters using calculus in an existing second order rotatable design of twenty-six points. Such a design permits a response surface to be fitted easily and provides spherical information contours besides the realizations of optimum combination of ingredients in Agriculture, horticulture and allied sciences which results in economic use of scarce resources in relevant production processes. The expected second order rotatable design model in three dimensions is available where the responses would then facilitate the estimation of the linear and quadratic coefficients. An example involving Phosphate ( $\left.\mathrm{x}_{1 \mathrm{u}}\right)$, Nitrogen ( $\left.\mathrm{x}_{2 \mathrm{u}}\right)$ and Potassium ( $\left.\mathrm{x}_{3 \mathrm{u}}\right)$ is used to represent the three factors in the coded level and converted into natural levels.
\end{abstract}

Keywords:Response Surface Methodology; Second Order Design; Optimality; Coded levels; Natural levels.

\section{Introduction}

Response Surface Methodology is a powerful and efficient mathematical approach widely applied in the optimization of cultivation process. The world is facing food shortage and the search for alternative or improve measures is inevitable in agricultural fields. Since arable land is a fraction so we need to produce maximally in such areas by utilizing design of experiment like the one design in this study. The main objective of the experimenter is usually to estimate the absolute response or the parameters of a model providing the relationship between the response and the factors. In this context, rotatable designs were introduced by Box and Hunter [3] in order to explore the response surface. They developed second order rotatable design through geometrical configurations. Draper [5] says a second order rotatable design aids the fitting of a second order surface and provides spherical information contours. Bose and Draper [2] point out that the technique of fitting a response surface is one widely used to aid in the statistical analysis of experimental work in which the response of a product depends, in some unknown fashion, on one or more controllable variables. Before the details of such analysis can be carried out, experiments must be performed at predetermined levels of the controllable factors, that is, an experimental design must be selected prior to experimentation. Draper and Beggs [6] state that once an experimenter has a polynomial model of suitable order, the problem arises as how best to choose the settings for the independent variables over which he has control. A particular selection of settings or factor levels, at which observations are to be taken is called a design. Designs are usually selected to satisfy some desirable criteria chosen by the experimenter. These criteria include the rotatability criterion and the criterion of minimizing the mean square error of estimation over a given region in the factor space. The present work represents an attempt to meet, in part, this need using the rotatability criterion. Rotatable designs have the nice property that the variance of the estimated response is constant at points equidistant from the centre of the design, conventionally taken to be the origin of the factor space, after transformations if necessary. Rotatable designs generate information about the response surface equally in all directions and are therefore useful when no or little prior knowledge is available about the nature of the response surface. The class of rotatable designs is also very rich in the sense that under many commonly used criteria, such as D-optimality, the optimal designs for polynomial regression models over hyperspherical regions may be found within this class Kiefer [7]. Because of the above reasons, a large volume of literature in experimental design is devoted to the investigation of properties and constructional problems of rotatable designs. 


\section{Construction of twenty-six points specific optimum second order rotatable designs in three dimensions}

Kosgei et al, [8] gave criteria of selecting the optimality of a design based on known classical optimality criteria. Bose and Draper [2] define certain transformations applied to points in three dimensions. Let $\mathrm{W}(\mathrm{x}, \mathrm{y}, \mathrm{z})=(\mathrm{y}, \mathrm{z}, \mathrm{x}), \mathrm{W}^{2}=(\mathrm{x}, \mathrm{y}, \mathrm{z})=(\mathrm{z}, \mathrm{x}, \mathrm{y}), \mathrm{W}^{3}=(\mathrm{x}, \mathrm{y}, \mathrm{z})=(\mathrm{x}, \mathrm{y}, \mathrm{z})$ $\mathrm{W}^{3}=\mathrm{I}$ the unit matrix

Thus I, W, $\mathrm{W}^{2}$ form a cyclic group of linear transformation in three dimensions.

Further, let $\mathrm{R}_{1}(\mathrm{x}, \mathrm{y}, \mathrm{z})=(-\mathrm{x}, \mathrm{y}, \mathrm{z}), \mathrm{R}_{2}(\mathrm{x}, \mathrm{y}, \mathrm{z})=(\mathrm{x},-\mathrm{y}, \mathrm{z})$, and $\mathrm{R}_{3}(\mathrm{x}, \mathrm{y}, \mathrm{z})=(\mathrm{x}, \mathrm{y},-\mathrm{z})$, but $\mathrm{R}^{2}{ }_{1}=\mathrm{R}^{2}{ }_{2}=\mathrm{R}^{2}{ }_{3}=\mathrm{I}$

The four transformations of coordinates represented by $W, R_{1}, R_{2}$ and $R_{3}$ generate a group $G$ of transformations of order 26 with elements $W^{j}, W^{j} R_{1}, W^{j} R_{2}, W^{j} R_{3}, W^{j} R_{2} R_{3}, W^{j} R_{3} R_{1}, W^{j} R_{1} R_{2}, W^{j} R_{1} R_{2} R_{3}$ $(j=1,2,3)$

It is easily seen that all the 26 elements in (2.1) are distinct. While $R_{1}, R_{2}$ and $R_{3}$ commute, $W^{j}$ and $R_{j}$ do not (i,j=1,2,3). The 26 points of $\mathrm{G}(\mathrm{x}, \mathrm{y}, \mathrm{z})$ will coincide in pairs or in triplets or in quadruplets. The following is the design of twenty-six points that the free parameters $\mathrm{f}$, $\mathrm{a}, \mathrm{c}$ is determined.

$D=\left[\frac{1}{2} G(f, f, 0)+\frac{1}{3} G(a, a, a)+\frac{1}{4} G(c, 0,0)\right]$

We shall consider the above set of twenty-six points from Draper [5] and Mutiso [10].

The set of twenty-six points in (2.2) form a second order rotatable arrangement in three dimensions if the following moment conditions hold

$\sum_{u=1}^{26} x_{i u}^{2}=8 f^{2}+8 a^{2}+2 c^{2}=26 \lambda_{2}$
$\sum_{u=1}^{26} x_{i u}^{4}=8 f^{4}+8 a^{4}+2 c^{4}=78 \lambda_{4}$
$\sum_{u=1}^{26} x_{i u}^{2} x_{j u}^{2}=4 f^{4}+8 a^{4}=26 \lambda_{4}$

(For $\mathrm{i} \neq \mathrm{j}=1,2,3$ ) and all other sums of products and powers up to and including order four are zero.

The excess of $\sum_{\mathrm{u}=1}^{26} \mathrm{x}_{\mathrm{iu}}^{4}=3 \sum_{\mathrm{u}=1}^{26} \mathrm{x}_{\mathrm{iu}}^{2} \mathrm{x}_{\mathrm{ju}}^{2}$

Is denoted by

$\mathrm{D}=\{\mathrm{G}(\mathrm{f}, \mathrm{f}, 0)+\mathrm{G}(\mathrm{a}, \mathrm{a}, \mathrm{a})+\mathrm{G}(\mathrm{c}, 0,0)\}=$

$\sum_{\mathrm{u}=1}^{26} \mathrm{x}_{\mathrm{iu}}^{4}-3 \sum_{\mathrm{u}=1}^{26} \mathrm{x}_{\mathrm{iu}}^{2} \mathrm{x}_{\mathrm{ju}}^{2}=2 \mathrm{f}^{4}+8 \mathrm{a}^{4}-\mathrm{c}^{4}=0$

we let $\mathrm{f}^{2}=\mathrm{xc}^{2}$ and $\mathrm{a}^{2}=\mathrm{yc}^{2}$

Substituting these parameters we obtain

$2 \mathrm{x}^{2} \mathrm{c}^{4}+8 \mathrm{y}^{2} \mathrm{c}^{4}-\mathrm{c}^{4}=0$

$c^{4}\left(2 x^{2}+8 y^{2}-1\right)=0$

$2 \mathrm{x}^{2}+8 \mathrm{y}^{2}-1$

$\mathrm{x}^{2}=\frac{1-8 \mathrm{y}^{2}}{2}$

which gives $x=\left(\frac{1}{2}-4 y^{2}\right)^{\frac{1}{2}}$

Implying that $0<y<\sqrt{\frac{1}{8}}=0.353553$

Specifically, when $\mathrm{y}=0.15$ then $\mathrm{x}=0.640312$

Implying that in (2.3).

$\mathrm{f}^{2}=0.640312 \mathrm{c}^{2} \equiv \mathrm{f}=0.800195 \mathrm{c}$

$\mathrm{a}^{2}=0.15 \mathrm{c}^{2} \equiv \mathrm{a}=0.387298 \mathrm{c}$

The points form second order specific rotatable arrangement in three dimensions in the twenty six points if the non-singularity condition of rotatability

$\frac{\lambda_{4}}{\lambda_{2}^{2}}>\frac{\mathrm{k}}{\mathrm{k}+2}$ is satisfied

$\lambda_{2}=\frac{1}{26} \sum_{\mathrm{u}=1}^{26} \mathrm{x}_{\mathrm{iu}}^{2}=\frac{8\left(0.640312 \mathrm{c}^{2}\right)+8\left(0.15 \mathrm{c}^{2}\right)+2 \mathrm{c}^{2}}{26}$

$\lambda_{2}=0.320096 \mathrm{c}^{2}$

$\lambda_{4}=\frac{1}{26} \sum_{\mathrm{u}=1}^{26} \mathrm{x}_{\mathrm{iu}}^{2} \mathrm{x}_{\mathrm{ju}}^{2}=\frac{4\left(0.640312 \mathrm{c}^{2}\right)^{2}+8\left(0.15 \mathrm{c}^{2}\right)^{2}}{26} \mathrm{c}^{4}$

$\frac{\lambda_{4}}{\lambda_{2}^{2}}=\frac{0.0 .07000 \mathrm{c}^{4}}{\left(0.320096 \mathrm{c}^{2}\right)^{2}}=0.683183>\frac{\mathrm{k}}{\mathrm{k}+2}=0.6$

Mutiso(1998) shows that the expansion of $\operatorname{var}\left(\mathrm{y}_{\mathrm{u}}\right)$ is given by

$\operatorname{var}\left(\hat{\mathrm{y}}_{\mathrm{u}}\right)=\frac{\beta \sigma^{2}}{\mathrm{~N}}\left\{2(\mathrm{k}+2) \beta_{2}^{2}+\left[(\mathrm{k}+2) \beta_{2}-(\mathrm{k}-1)\right] 3 \mathrm{k} \beta_{2}-4 \mathrm{k} \beta_{2}-2\left(\beta_{2}-1\right) \beta_{2} \mathrm{k}(\mathrm{k}-1)-\frac{\mathrm{k}}{\lambda_{2}}-\frac{\lambda_{2} \mathrm{k}(\mathrm{k}-1)}{\beta_{2}}\right\}$

Where 


$$
\beta=\left[2 \beta_{2}\left((\mathrm{k}+2) \beta_{2}-\mathrm{k}\right]^{-1} \text { and } \beta_{2}=\frac{\lambda_{4}}{\lambda_{2}^{2}} \neq \frac{\mathrm{k}}{\mathrm{k}+2}\right.
$$

Where

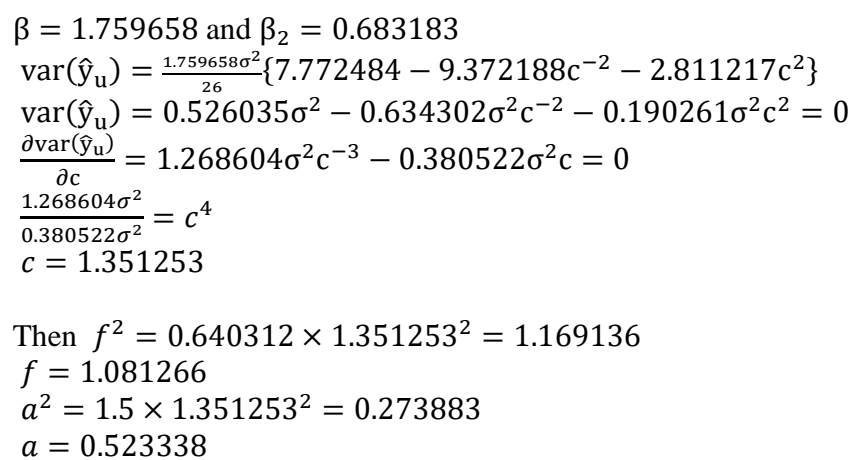

\section{A Practical hypothetical example}

A central composite rotatable design was set up to investigate the effects of three fertilizer ingredients on the yield of hybrid maize in Rift Valley to illustrate the use of the specific optimum second order rotatable designs of twenty six points under field conditions.

The fertilizer ingredients and actual amount applied were phosphoric acid $\left(\mathrm{P}_{2} \mathrm{O}_{5}\right) \mathrm{x}_{1}, \Psi_{1}=30$ milligram/hole; Nitrogen $(\mathrm{N}) \mathrm{x}_{2} \Psi_{2 .}=25$ milligram/hole; and potash $\left(\mathrm{K}_{2} \mathrm{O}\right) \mathrm{x}_{3} \Psi_{3 .}=40 \mathrm{milligram} / \mathrm{hole}$. The response of interest is the average yield in mg per hole of hybrid Maize $D=\left[\frac{1}{2} G(1.081266,1.081266,0)+\frac{1}{3} G(0.523338,0.523338,0.523338)+\frac{1}{4} G(1.351253,0,0)\right]$

The result of soil mapping investigations indicated deficiencies of these minerals elements in the rift-valley loam soil. The original letters $\mathbf{f}, \mathbf{a}$ and $\mathbf{c}$ represent the variation in quantity application of a factor due to soil fertility gradient culminating in several radii manifestations of rotatability criterion.

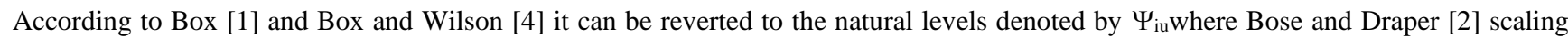
condition fixes a particular design when $\lambda_{2}=1$ where $\boldsymbol{x}_{\boldsymbol{i} \boldsymbol{u}}=\frac{\Psi_{i u}-\Psi_{i}}{S_{i}}$ and $\Psi_{i .}=\frac{\sum_{u=1}^{N} \Psi_{i u}}{N}$.

$\sum_{u=1}^{N} x_{i u}^{2}=N$ and $\sum_{u=1}^{N} x_{i u}=0$

$$
\begin{gathered}
S_{i}=\left[\frac{\sum_{u=1}^{N}\left(\Psi_{i u}-\Psi_{i .}\right)}{N}\right]^{0.5} \\
\Psi_{i .}=x_{i u} S_{i}+\Psi_{i .}
\end{gathered}
$$

The value 30mg, $25 \mathrm{mg}$ and $40 \mathrm{mg} /$ hole represent the centers of the value for Phosphoric acid, Nitrogen and Potash respectively. The design matrix can be constituted but the evaluation of the inverse will be a major computational project to estimate the coefficients of the second order rotatable design model which give the optimum response or yield

Let the scale parameter as in Koske [9]

$\mathrm{S}_{\mathrm{i}}$, assume $\mathrm{s}_{1}=0.5, \mathrm{~s}_{2}=0.3$ and $\mathrm{s}_{3}=1$

To estimate the coefficients

$\beta_{o}, \beta_{1}, \beta_{2}, \beta_{3}, \beta_{11}, \beta_{22}, \beta_{33}, \beta_{12}, \beta_{13}$ and $\beta_{23}$ in the expected second order rotatable design model in three dimensions

$$
y_{u}=\beta_{0} x_{0 u}+\beta_{1} x_{1 u}+\beta_{2} x_{2 u}+\beta_{3} x_{3 u}+\beta_{11} x_{1 u}^{2}+\beta_{22} x_{2 u}^{2}+\beta_{33} x_{3 u}^{2}+\beta_{12} x_{1 u} x_{2 u}+\beta_{13} x_{1 u} x_{3 u+} \beta_{23} x_{2 u} x_{3 u}+\varepsilon_{u}
$$

We require field observation of the yield

$$
y_{u}(u=1,2, \ldots, 26)
$$

\begin{tabular}{|c|c|c|c|c|c|}
\hline \multirow{2}{*}{$\frac{\text { Coded Values }}{\left(\mathrm{x}_{1} \mathrm{u}\right.}$} & \multicolumn{5}{|c|}{ Natural Values } \\
\hline & $\mathrm{X}_{2} \mathrm{u}$ & $\left.\mathrm{x}_{3} \mathrm{u}\right)$ & $\Psi_{1} \mathrm{u}$ & $\Psi_{2} \mathrm{u}$ & $\Psi_{3} \mathrm{u}$ \\
\hline (1.081266 & 1.081266 & $0)$; & 30.540633 & 25.324380 & 40 \\
\hline$(-1.081266$ & 1.081266 & $0)$; & 29.459367 & 25.324380 & 40 \\
\hline (1.081266 & -1.081266 & $0)$; & 30.540633 & 24.675620 & 40 \\
\hline$(-1.081266$ & -1.081266 & $0)$; & 29.459367 & 24.675620 & 40 \\
\hline (1.081266 & 0 & 1.081266); & 30.540633 & 25 & 41.081266 \\
\hline
\end{tabular}

The complete second order model to be fitted to yield values is

$$
y_{u}=\beta_{0}+\sum_{i=1}^{26} \beta_{i} x_{i}+\sum_{i=1}^{26} \beta_{i i} x_{i}^{2}+\sum_{i=1}^{25} \sum_{j=2}^{26} \beta_{i j} x_{i} x_{j}+e
$$

The following table list the design setting of $\mathrm{x}_{1}, \mathrm{x}_{2}$ and $\mathrm{x}_{3}$ and the observed values at 26 design points $\mathrm{P}_{2} \mathrm{O}_{5}, \mathrm{~N}, \mathrm{~K}_{2} \mathrm{O}$ and yield are in mg 


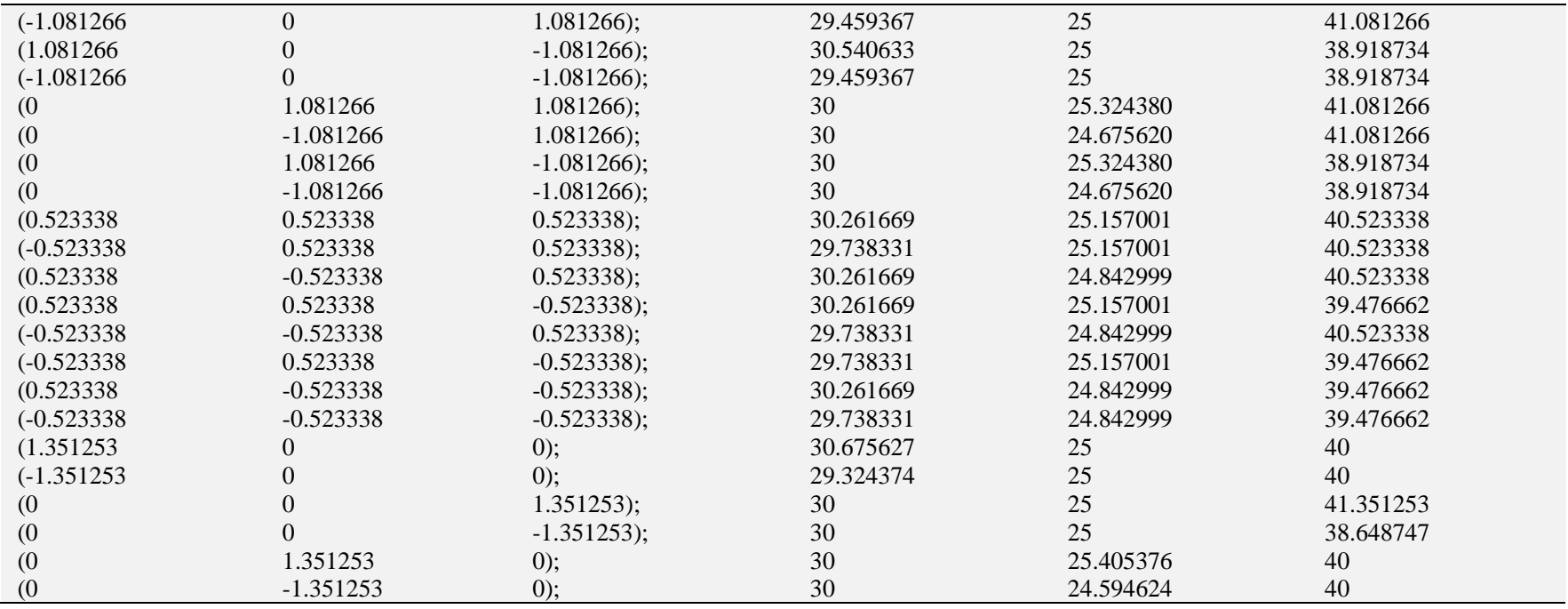

But $\mathrm{c}=1.351253$ then

$\lambda_{2}=0.320096 c^{2}=0.584458$

$\lambda_{4}=0.070000 c^{4}=0.233398$

\section{Applications}

It is always possible, especially in a new field of experiment, to make an unfortunate selection of units and again it is solely a question of judgment. This design permits a response surface to be fitted easily and provides spherical information contours besides the realizations of optimum combination of ingredients in Agriculture, horticulture and allied sciences which results in economic use of scarce resources in relevant production processes. The design enable us to see that the specific optimum second order design of three dimensions in twenty six points are met and the expected second order rotatable design model in three dimensions is available when an experimenter would carry out an experiment where the responses would then facilitate the estimation of the linear and quadratic coefficients.

\section{Conclusion}

This study utilizes response surface methodology to obtain mathematical parameters of coded values and its corresponding natural levels that could approximate the functional relationship between performance characteristics and design variables. After an experimenter has done the experiment the resulting response is used to construct response surface approximation model using least squares regression analysis. However, in physical experiments there is usually some variability in the output response with the experiment repeated with the same inputs, so it is not automatic, judgment must be applied to get "good" response. Nowadays, the over use of N (Nitrogen) relative to $\mathrm{P}_{2} \mathrm{O}_{5}$ (Phosphate) and $\mathrm{K}_{2} \mathrm{O}$ (Potassium) concerns both from agronomic and environmental perspective. Phosphate and Potassium fertilizers have been in short supply and farmers have been more steadily adopting the use of nitrogenous fertilizers because of impressive virtual response. There is evidence that soil $\mathrm{P}_{2} \mathrm{O}_{5}$ and $\mathrm{K}_{2} \mathrm{O}$ level are declining. So, determining the optimum balance of $\mathrm{P}_{2} \mathrm{O}_{5}, \mathrm{~N}_{\text {and }} \mathrm{K}_{2} \mathrm{O}$ so as to produce high yield of hybrid maize has been an important issue.

\section{References}

[1] Box, G.E.P. (1952). Multifactor designs of first order. Journal of Biometrika 39:49-57https://doi.org/10.1093/biomet/39.1-2.49.

[2] Bose, R. C. and Draper, N.R. (1959). Second order rotatable designs in three dimensions. Ann. Math. Stat., Vol. 30, pp. 10971112.https://doi.org/10.1214/aoms/1177706093.

[3] Box, G.E.P. and Hunter, J.S. (1957). Multifactor experimental designs for exploring response surfaces. Ann.Math.Statist. 28,195241https://doi.org/10.1214/aoms/1177707047.

[4] Box G.E.P, Wilson K.B. (1951). On the Experimental Attainment of Optimum Conditions.Journal of the Royal Statistical Society B, 13, 145.https://doi.org/10.1111/j.2517-6161.1951.tb00067.x.

[5] Draper N.R. (1960). Second order rotatable designs in four or more dimension. Ann. Math. Stat., Vol. 31, pp. 2333.https://doi.org/10.1214/aoms/1177705984.

[6] Draper, N.R. and Beggs, W.J. (1971). Errors in the factor levels and experimental design. Journal Annals of Mathematical Statistics 41:46-48. https://doi.org/10.1214/aoms/1177693493.

[7] Kiefer, J.C. (1960). Optimum experimental designs V, with applications to systematic and rotatable designs. In Proceedings of the Fourth Berkeley Symposium on Mathematical Statistics and Probability, Berkeley, CA 1960, Volume 1 (Ed. J. Neyman). University of California, Berkeley, CA, 381-405.

[8] Kosgei, M.K., Koske, J.K., Too, R.K., and Mutiso, J.M. (2006). On optimality of a second order rotatable design in three dimensions. The east Africa journal of statistics 2:123-128. https://doi.org/10.4314/eajosta.v1i2.39162.

[9] Koske J.K., Mutiso J.M. Kosgei M.K. (2008). A specific optimum second order rotatable designs of twenty-four points with a practical example. Vol. 1 issues no. 1, East African Journal of pure \& applied science.

[10] Mutiso, J. M. (1998). Second and Third Order Specific and Sequential Rotatable Designs in K Dimensions. Unpublished D.Phil. Thesis, Moi University. 